IOSR Journal of Pharmacy

e-ISSN: 2250-3013, p-ISSN: 2319-4219, www.iosrphr.org

Volume 2 Issue 6 || $\mid$ Nov-Dec. 2012 || | PP.43-46

\title{
Detection of tumor associated antigens in blood plasma of tumor bearing cattle and buffalo
}

\author{
Hari Mohan Saxena ${ }^{1 *}$, Raman Chopra ${ }^{2}$ \\ ${ }^{1,2}$ Department of Veterinary Microbiology, College of Veterinary Science, \\ Guru Angad Dev Veterinary and Animal Sciences University, Ludhiana - 141004 India
}

\begin{abstract}
SDS - Polyacrylamide Gel Electrophoresis (SDS PAGE) of blood plasma from three cattle and one buffalo affected with various tumors (odontoma, nasal granuloma and horn cancer in cattle and teat tumor in buffalo) revealed the presence of new proteins $p 51, p 53$ and p71-72 in all the samples which were not present in plasma from normal healthy bovines. However, another protein, p77.5 present in normal plasma samples was absent in the plasma of only one (horn cancer affected) out of three tumor affected cows. The possibility of these proteins as markers of tumorigenesis is discussed.
\end{abstract}

Keywords-Tumors, tumor associated antigens, differentiation antigens, cattle, buffalo.

\section{INTRODUCTION}

Cancer cells undergo many changes in their plasma membranes and may acquire new antigens which can induce immunological response. Thus, the objective of this study was to identify the antigenic characteristics of tumors which are different from those of normal tissues. Several tumor markers have been identified on tumor cells and in the sera of tumor bearing animals. Some proteins in serum have also been claimed to be tumor

Markers. Tumor associated antigens (TAAs) shed in the serum / plasma could be identified by PAGE. Although considerable work has been done on human TAAs, work on TAAs of cattle and buffaloes is limited. Therefore, this study on TAAs of bovines was undertaken.

\section{MATERIALS AND METHODS}

Tumor bearing animals: PAGE analysis was carried out on plasma from 4 different confirmed tumors of bovines ( 3 cattle and 1 buffalo). All the cases were confirmed histopathologically for the type of tumor.

Healthy control animals: Samples from normal healthy bovines were used in the study.

Plasma samples: Blood was collected aseptically in heparinized syringe and clear plasma was obtained after centrifugation at $1000 \mathrm{~g}$ for 15 minutes at $4^{\circ} \mathrm{C}$. After adding $0.01 \%$ Merthiolate as preservative, plasma samples were stored at $-20^{\circ} \mathrm{C}$ till used.

SDS - PAGE: All the plasma samples collected from tumor - bearing animals were analyzed electrophoretically to identify any tumor associated proteins. The plasma samples were diluted in $8 \mathrm{M}$ Urea to dissociate any immune complexed TAAs. PAGE was done using the method of Laemmli [1] with minor modifications. Discontinuous SDS PAGE gels consisting of stacking and resolving gels of 5\% and 12\%, respectively, were used. Samples with $50 \square$ g protein each were loaded in the wells. The samples were subjected to electrophoresis for 1 hour at $200 \mathrm{~V}$. Along with the samples, normal plasma and standard molecular weight markers were also run in each gel. The molecular weight standard consisted of a mixture of egg white lysozyme $(14.3 \mathrm{kDa}), \square \square$ Lactoglobulin $(18.4 \mathrm{kDa})$, egg albumin $(45 \mathrm{kDa})$, and bovine serum albumin $(66 \mathrm{kDa})$, respectively. Gels were stained for 30 minutes in $0.01 \%$ Coomassie Blue R-250 in fixative (10\% acetic acid and $40 \%$ methanol) and were destained for $1-3$ hours in fixative.

\section{RESULTS AND DISCUSSION}

Samples from tumor bearing animals: Plasma and tissue samples from cattle and buffalo affected with different tumors were collected. The tumors in cattle were on the gums, nasal cavity and horn, respectively. The buffalo had a teat tumor.

Histopathological findings: In cattle, the tumors of gums and nasal cavity were odontoma and granuloma, respectively, and the horn cancer was a squamous cell carcinoma with hard granules. The buffalo teat tumor was also confirmed histopathologically. 


\section{Plasma protein profiles in tumor bearing bovines:}

New protein bands detected by SDS PAGE in plasma of tumor bearing animals:

Plasma protein profiles from all the 4 bovines with various tumors showed the presence of new protein bands of $51 \mathrm{kDa}, 53 \mathrm{kDa}$ and 71-72 kDa, respectively (Tables $1 \& 2$, Figs. $1 \& 2$ ).

Protein bands absent in SDS-PAGE plasma protein profiles of tumor bearing bovines:

Out of the 4 plasma samples from bovines with different tumors, only one from the horn cancer affected animal showed the absence of $77.5 \mathrm{kDa}$ normal protein band (Table 2).

The SDS-PAGE analysis of plasma samples from tumor bearing bovines revealed some interesting patterns of presence or absence of specific protein bands in the plasma protein profiles. In all, 3 new protein bands (p51, p53 and p71-72) were identified in the plasma protein profiles of tumor bearing bovines. These bands were absent in the plasma from unaffected animals.

The presence of $52 \mathrm{kDa}$ protein in the sera of breast cancer patients has been reported [2]. The relationship between human breast cancer and its mouse counterpart, the virus induced mouse mammary tumor was also noticed. The carcinoma antigen of $50 \mathrm{kDa}, \mathrm{CA}-50$ has been detected earlier [3] in the sera of patients with a large variety of epithelial carcinomas including mammary tumor, but not in normal healthy individuals.

In our present study, most of the tumor bearing animals showed the presence of proteins p51 and p53 in their plasma. The excessive shedding of high and low molecular weight CEA and related proteins $(30-100$ $\mathrm{kDa}$ ) under the influence of alpha interferon and PGE-2 in various carcinomas has been reported [4]. Protein antigens, mostly p51 and p53, have also been detected in the sera of patients with venereal granuloma. It has been reported [5] that CA-50 is present as glycoprotein and glycolipid, in 69\% of cases of carcinoma of uterus. A protein of molecular weight $48 \mathrm{kDa}$ was detected [6] in the sera of patients with cervical cancer. A precipitin band specific to bovine horn cancer was reported [7]. Cells from ocular squamous cell carcinoma (OSCC) in cattle possess tumor associated antigens that are common to most of the OSCC cells [8].

The present study also revealed the consistent presence of p71/72 in tumor affected bovines. Cattle with enzootic bovine leucosis possess common TAA, partially common TAA, and specific TAA [9]. A $74 \mathrm{kDa}$ TAA was present in cattle with enzootic bovine leucosis. The presence of TAA of $73 \mathrm{kDa}$ in cattle with BLV has been reported [10]. A $72 \mathrm{kDa}$ protein has earlier been reported in colorectal cancer [11]. A $70 \mathrm{kDa}$ TAA has been detected in patients with epithelial cancer [12]. A $70 \mathrm{kDa}$ TAA in patients with skin cancer has also been reported [13].

In our study, proteins p51, p53 and p71-72 were found to be present in plasma of bovines with various tumors. In particular, p51 and p53 were found to be consistently present in all the cases of bovine tumors (mostly epithelial tumors) included in the study. TAAs were found widely distributed in different types of tumors as in neuroblastoma and leukemia [14]. A TAA shared by breast cancer and other carcinomas and another one shared by neuroblastoma, lung and breast cancer have been reported [15].

In the present study, the proteins like p51, p53 and p71-72 were found in plasma specifically from tumor cases, irrespective of the tumor type. TAAs have earlier been isolated from 4 different tumors, breast cancer, colon carcinoma, melanoma and hepatoma [16]. The antigens from all the 4 tumors gave similar patterns of protein bands on SDS-PAGE, yet each was specific for the tumor of origin. They proposed that tumor may contain TAAs of very similar structure, although of different antigenic specificity and that these TAAs might be modified HLA antigens.

The overexpression of p53 plays important part in the development of many squamous cell carcinomas in cattle, particularly the ocular carcinoma [17]. The new protein bands of 51 and $53 \mathrm{kDa}$, found in our study to be exclusively present in plasma of tumor bearing animals, irrespective of the tumor type and species affected, but absent in normal healthy animals, call for further studies as they may be possible tumor markers in these animal tumors.

The SDS-PAGE analysis of plasma from tumor bearing animals also showed the absence of a protein p77.5 in the plasma of one animal suffering from horn cancer, which was present in plasma of normal cattle. The absence of normal skin specific antigens has also been reported in squamous cell carcinomas, basal cell carcinomas and sweat gland carcinomas [18]. The loss of some normal liver antigens during carcinogenesis has also been observed by others $[19,20]$.

It is well known that during tumor development, the cells undergo dedifferentiation which could possibly be responsible for the absence of the differentiation associated protein(s) in serum / plasma of tumor bearing animals. Such protein(s) may possibly be differentiation antigen(s) which may have been lost during the tumorigenesis. It may be possible that p77.5 found to be lost in an animal tumor in our study, could be a possible differentiation - associated antigen. However, more studies on a larger number of animals with different tumors are needed to confirm this observation. 


\section{CONCLUSIONS}

Proteins p51, p53 and p71-72 were detected in plasma from tumor bearing animals but were found absent in normal healthy bovines. Protein p77.5 present in the plasma of normal bovines was found absent in the plasma of a horn cancer affected cow but not in bovines with other tumors.

\section{REFERENCES}

[1]. Laemmli, V. K. Cleavage of structural protein during the assembly of the head of bacteriophage T4. Nature 227, 1970, 680-681.

[2]. Moore, D. H., Moore, D. H. II, and Moore, C. T. Relationship of human breast cancer with mouse mammary tumor. Adv. Cancer Res. 40, 1983, 189-253.

[3]. Nilsson, O., Lindholm, L., Persson, B., Fredman, P., Mannson, J. E., Holmgren, J. and Svennerholm, L. Detection of CA-50 in human epithelial carcinomas. Proc. Int. Symp. Glycoconjugates 1983, 852-853.

[4]. Yamaguchi, N. and Kawai, K. Gastroenterology 18, 1983, 428-435.

[5]. Lindholm, L., Nilsson, O., Lagergard, T., Mason, J. E., Persson, B., Svennerholm, L. and Holmgren, J. Tumor Biol. 1984, 63-78.

[6]. Kato, H., Miyauchi, F., Morioka, H., Fujino, T. and Torigoe, T. Detection of tumor associated antigen in sera and urine of patients with cervical cancer. Cancer 43, 1979, 585-590.

[7]. Pachauri, S. P. and Pathak, R. C. Histochemical and immunochemical studies on bovine horn cancer. Orissa Vet. J. 5, 1970, 11-14.

[8]. Kuchroo, V. K. and Spradbrow, P. B. Tumor associated antigens in bovine ocular squamous cell carcinoma: studies with sera from tumor bearing animals. Vet. Immunol. Immunopathol. 9(1), 1985, 23-26.

[9]. Aida, Y., Onuma, M., Mikami, T. and Izawa, H. Topographical analysis of tumor associated antigens on bovine leukemia virus induced bovine lymphosarcoma. Cancer Res. 45(3), 1985, 1181-1186.

[10]. Bicka, L., Grudboeck-Jusko, J., Kuzmak, J., Jedrazejewska, M. and Kozaczynska, B. Isolation of tumor associated antigen from bovine lymphoid tumors and detection of TAA antibodies in cows affected with bovine leukemia virus. Bull. Vet. Instt. Pulawy (Cf. Vet. Bull. 1994 No. 11, Ref. No. 7113).

[11]. Colcher, D., Hand, P. H., Nuti, M. and Schlom, J. A spectrum of monoclonal antibodies reactive with human mammary tumor cells. Proc. Natl. Acad. Sci. USA 78, 1981, 3199-3203.

[12]. Dippold, W. G., Lloyd, K. O., Li, L. T., Ikeda, H., Oettgen, H. F. and Old, L. J. Proc. Natl. Acad. Sci. USA 77, 1980, 6114-6118.

[13]. Natali, P. G., Wilson, B. S., Imai, K., Bigotti, A. and Ferrone, S. Cancer Res. 42, 1982, 583-589.

[14]. Kennett, R., Jonak, Z. and Bechtol, K. B. Prog. Cancer Res. Ther. 12, 1980, 209-219.

[15]. Kufe, D. W., Nadler, L., Sargent, L., Shapiro, H., Hand, P., Austin, F., Colcher, D. and Schlom, J. Cancer Res. 43, 1983, 851-857.

[16]. Thomson, D. M., Tataryn, D. N. and Schwartz, R. Tumor-associated antigens in affinity eluates from breast and colon cancer patients. Br. J. Cancer 41, 1980, 86-99.

[17]. Teifke, J. P. and Lohr, C. V. Immunohistochemical detection of p53 overexpression in paraffin wax embedded squamous cell carcinoma of cattle, horse, cats and dogs. J. Comp. Path. 114, 1996, 205-210.

[18]. Nairn, R. C. Fluorescent protein tracing. ( $2^{\text {nd }}$ Edn.) Livingstone, Edinburgh 1962.

[19]. Sorof, S., Young, E. M., McCue, M. M. and Fatterman, P. L. Zonal electrophoresis of soluble proteins of liver and tumor in azo dye carcinogenesis. Cancer Res. 23, 1963, 864-882.

[20]. Abelev, G. I. Antigenic structure of chemically induced hepatoma. Prog. Exp. Tumor Res. 7, 1965, 1040-1057.

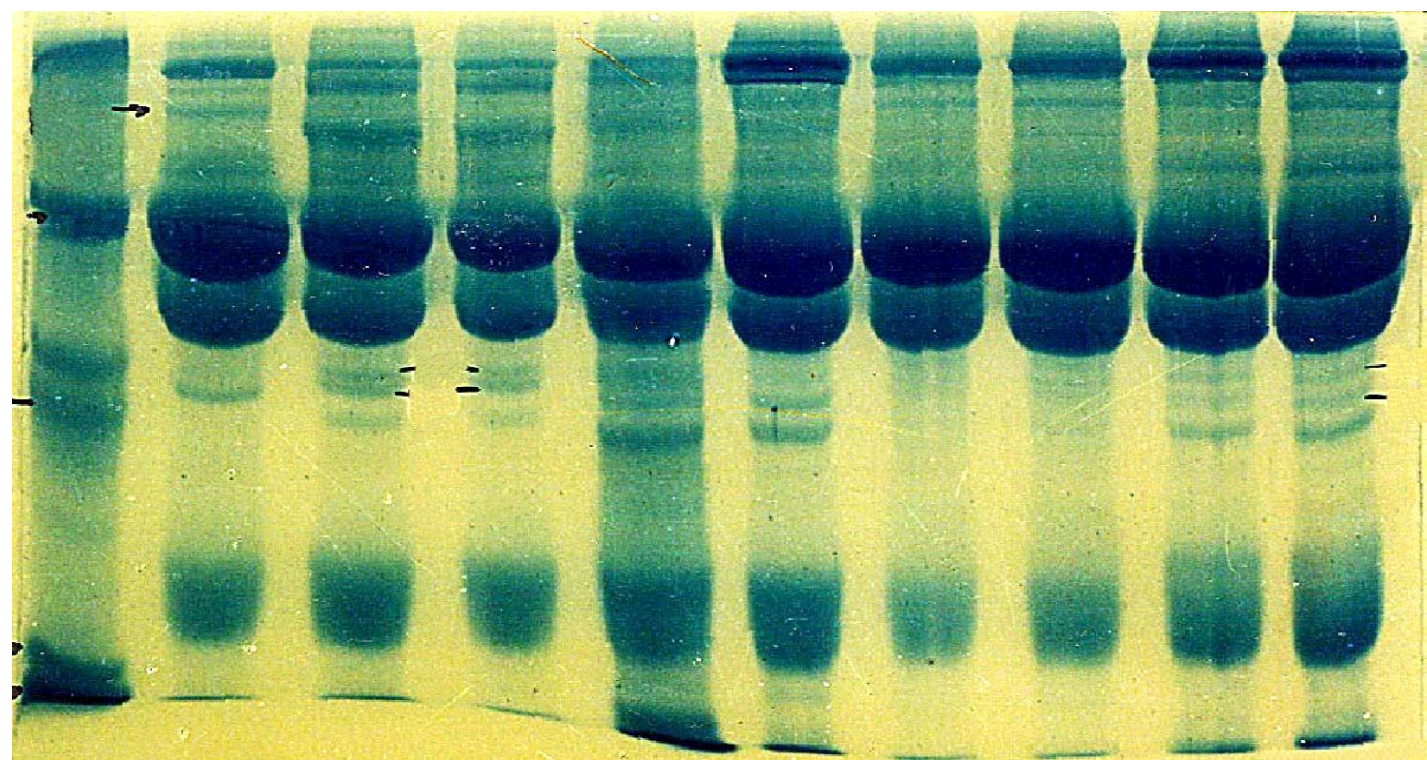

Fig. 1. SDS PAGE protein profile of bovine tumors 
Table 1. New protein bands detected by SDS-PAGE in the plasma of tumor bearing cattle and buffalo but absent in normal healthy bovines

\begin{tabular}{|l|l|l|}
\hline $\begin{array}{l}\text { S. } \\
\text { no. }\end{array}$ & $\begin{array}{l}\text { Protein bands } \\
(\text { kDa })\end{array}$ & $\begin{array}{l}\text { Number of tumor bearing animals } \\
\text { positive (out of 4) }\end{array}$ \\
\hline 1 & $71-72$ & 3 \\
\hline 2 & 53 & 3 \\
\hline 3 & 51 & 4 \\
\hline
\end{tabular}

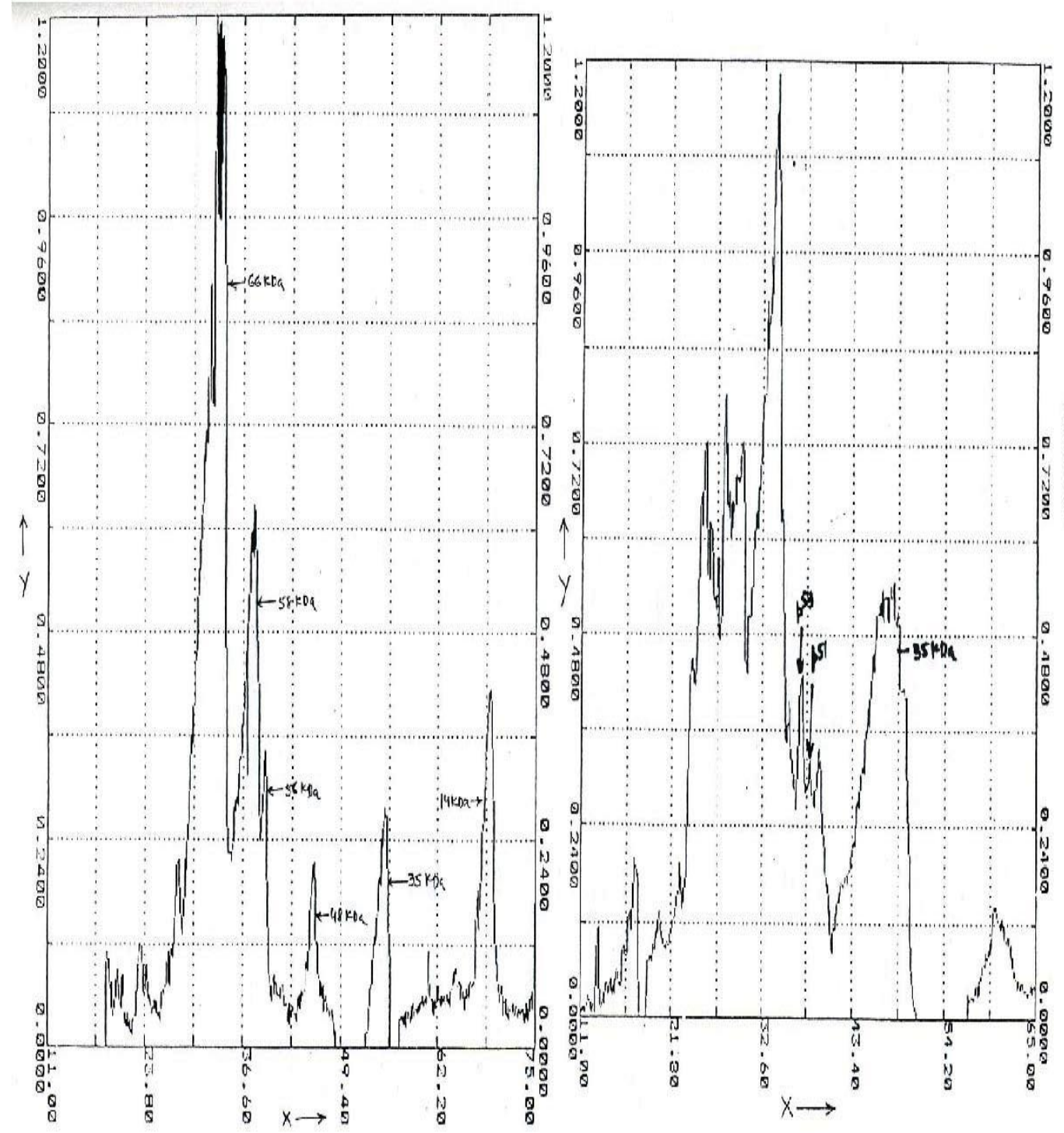

Fig. 2. Gel scans of normal and horn cancer affected cattle.

Table 2. Plasma protein profiles of cattle and buffalo with miscellaneous tumors

\begin{tabular}{|l|l|l|l|l|}
\hline $\begin{array}{l}\text { S. } \\
\text { no. }\end{array}$ & Species & Tumor type & $\begin{array}{l}\text { New protein } \\
\text { bands present }(\mathbf{k D a})\end{array}$ & $\begin{array}{l}\text { Normal protein bands } \\
\text { absent (kDa) }\end{array}$ \\
\hline 1 & \multirow{2}{*}{ Cattle } & Horn cancer & $72,53,51$ & 77.5 \\
\cline { 4 - 5 } & & Odontoma & 72,51 & - \\
\cline { 3 - 5 } & & Nasal granuloma & $72,53,51$ & - \\
\hline 4 & \multirow{2}{*}{ Buffalo } & Teat tumor & 53,51 & - \\
\hline
\end{tabular}

